\title{
Anecdotally evidence based
}

\author{
S Hancocks, OBE*
}

\author{
The wonderful thing about science is that science is a wonderful \\ thing.
}

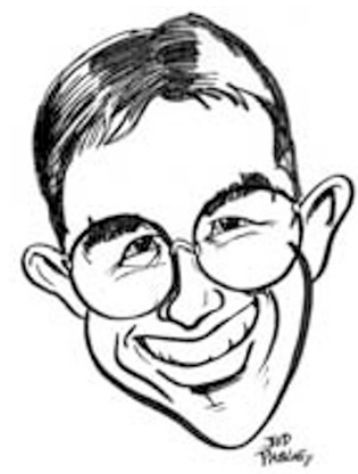

We are all used to the maxim 'well, it works for me.' We are what we eat and we are also the product of what we do every day, indeed what we have done day in, day out, for each of those saliva drenched hours that have formed our practice lives to date. So, if we've been taught this particular procedure or that specific technique and it apparently gets results we tend to stick with it. It seems to make sense. In terms of pure science though that simply isn't good enough. Is it evidence-based? The cry goes up. Well yes it is but it's anecdotally based evidence and that doesn't seem to count for much in the grand scheme of things.

Evidence based anything makes sense, of course it does, but just how far can you go with it? Surely there are some things we have to take on trust? I mean, how much evidence do we need?

Take the number 73 bus for example, actually and metaphorically. It has 'Victoria' on its destination blind and, standing at the stop in the blowing wind, we have to believe that it's actually going to go there. Based on past experience it seems mostly to have terminated at that regally named station on a regular (or irregular basis). Ah, say the evidence-based boffins, but how many times have you actually been on it all the way? It may indeed be that it just disappears as soon as it's gone round the corner, or that the passengers and crew conspire and take it off to Twickenham instead, or to Dollis Hill or Mortlake.

For such purists, the 'golden standard' is the RCT, no, not root canal treatment but randomised controlled trial. Which is fine if your patients are the sort who are randomised, controlled and, well let's face it many of them are indeed a trial, but that's not quite what is meant here. Carefully controlling for all possible variables that might alter or affect any given result, the researchers filter out the various influences that could upset their observations. Influences like patients arriving late, not brushing their teeth regularly, eating the wrong things when they say they're not, reporting that they use fluoride toothpaste twice a day when they don't, smoking behind the bike sheds and a myriad of other things that make them human. It might be randomised and it might be controlled but is it real? Does it pay the rent?

There's a problem too when it comes to writing up, and more importantly, reading the results of, such earnest research work. The August journal that you are holding now, none other than the BDJ has, over the years, been frequently castigated for publishing 'less than relevant papers on rat incisors' (although not, interestingly enough from the rat community itself). And there are times, glancing back over the

\section{Take the number 73} bus for example, actually and metaphorically. It has 'Victoria' on its destination blind and, standing at the stop in the blowing wind, we have to believe that it's actually going to go
there.

centuries when one could have agreed with such a sentiment. Even if, nowadays, the accusation is a little more difficult to sustain as researchers have taken note of the plaintive cry, 'yes, but what does it mean?' There are difficulties.

What, for example, should the average bod who's just seeing a conveyor belt of people with oral health needs make of something like: 'a multivariate logistic regression model revealed that subjects who were smokers, tested positive for Porphyromonas gingivalis, had five or more missing teeth, were not high school gradu- ates, and had not visited the dentist in the last five years were at a high risk of attachment loss of more than $1.5 \mathrm{~mm}$ around the distobucaal aspects of their upper second premolars'? And how to explain it in simple terms to the patients, especially as they are not high school graduates?

A further problem arises when you ask whether or not a particular piece of research indicates that a change in treatment patterns or behaviour is desirable, since nobody much ever wants to commit themselves. So, instead, you tend to get the answers hung around with all sorts of qualifying clauses and potential get-outs. 'Well, the outcome measures would seem to indicate that there is a trend towards a slightly greater effectiveness'. Or; 'overall, and taking into account the possible negative effect of the confounders there is a modest indication that the reproducible criteria for the subjectively interpreted components give a better-than-chance agreement that the modality may be effective in the intermediate term. Thank you.

Then again, there has to be more than a sneaking suspicion that 'value for money' is lurking somewhere in the background. It is perfectly reasonable to want not to waste funds but there is also a danger that the funds we spend on finding out if we are spending funds effectively exceeds the funds we would spend by following our anecdotally based instincts. But that would take a long term, multi-centre, meta-analysis study to confirm one way or another with the ultimate concern that the results would be equivocal. Or not.

We all want to find the magic solution, the silver bullet, and when it patently isn't available, primarily one suspects because we are dealing with real people and their stubborn refusal to conform, we still want to lay the blame at somebody's feet. Science or no, and unquestionably science is a wonderful thing, just while we're waiting, it may on the balance of probability be best to carry on doing the stuff that 'seems to work for me.' Only guessing mind you.

* The author is commissioning editor for the $\mathrm{BDJ}$. 